\title{
System Modelling of the Cereal Grading System in Tunisia
}

\author{
Lakhoua M.N. \\ Research Laboratory EI\&TIC \\ National Engineering School of Carthage, ENICarthage \\ University of Carthage \\ lnajeh@yahoo.fr
}

\begin{abstract}
After a presentation of the cereal activities in Tunisia, we present, according to a systemic analysis approach, the cereal grading system. A model describing the functioning of complex system was established and has allowed identifying the information that ruled it. An information matrix is defined and elaborated, it enables on the one hand to identify the produced and consumed information concerning each activity and on the other hand to determine the relations between the activities.
\end{abstract}

Key-words: Cereal grading, System modelling, Objective Planning Project by Objective (OOPP), Information System.

\section{INTRODUCTION}

The country alimentary security requires an efficient management of basic food resources that are necessary for the balance of its equilibrium socioeconomic system. This management depends on the global environment constituted by the production, consumption and transformation system.

Because of its geographic context, climatic environment and social tradition and culture, Tunisia with its alimentary tradition based particularly on the consumption of cereals, shows an important deficit of the national production and cereal consumption.

The management of its cereal Resources must be efficient and the transactions between the cereal purveyor (farmers producers, importation, stokers at a delivery) and the clients (farmers for seed, stokers at a conservation, millers, transformation industry: baking, alimentary pastes, animal nutrition...) must be excised by a coherent and objective process based on the $\underline{\boldsymbol{C} \text { - }}$ real grading system.

In fact, it's the grading system that determines the price of transactions at the sales and at the purchases of cereals and consequently that excited the technical and juridical relations between the different interveners.
The object of this paper is to present the grading system at the Office des Céréales (OC) in Tunisia and to apply a systemic approach exploiting the Planning Project by Objective (OOPP) method that allows achieving a reliable information analysis.

\section{CEREAL GRADING}

The determination of cereal quality, on transaction on the organised market, is an indispensable operation to evaluate the cereal product and its aptitude in storage. But in spite its importance, this evaluation besides done with a simplest manner based on visual appreciation and on the manager good meaning, particularly at level of collection, only for the criteria relative to specific height and, in some cases, to humidity ${ }^{[1]}$.

Besides cereals like any other biological product, change during their storage when they are bad conserved, causing degradations of quality and loss in quantity.

The official circuit taken by cereals locally produced begin at the level of collection and lead to transform units passing by Silos and storage Units.

At every step, cereals undergo a qualitative evaluation allowing to check their loyalty and to determine its commercial value.

This operation of quality evaluation of cereals is excised by an Grading scale ${ }^{[2]}$ at the time of all operation of entrance or exit of cereals which principal points are: Basic Price (BP); Improvement (to add to basic price if cereals have higher quality); Reduction (to reduce from basic price if cereals have a low quality). The cereal price is calculated:

\section{Cereal Price $=$ Basic Price + Improvement - Reduction}

The different steps of the cereal grading process are: taking samples, samples analysis (specific weight, humidity and impurities) and price determination. 


\section{ANALYSIS OF A CEREAL GRADING SYSTEM}

The model of cereal grading system that we propose means to describe the different activities of the process of cereal evaluation and to consider it like an information system.

This model is characterised by quality specifications (specific height, Humidity, impurities...) and management parameters (Reception, Analysis demand, Analysis results, Payment, Sampling ...).

The number, the complexity and the interference of information exchange taken in the study of a model, need a systemic approach defining the limits of the system (through establishing a communication between the outside environment) and identifying the principal activities and the parameters conditioning these activities ${ }^{[6]}$.

The OOPPmethod, based on ZOOPP (Ziel Orientierte Projekt Planung) method was used. This method ${ }^{[7][8]}$ identify all the activities hierarchically classified and their associated parameters : responsible, resources (infrastructure, equipment, human resources, logistic resources, information resources,...), timing, place, realisation indicators.

The OOPP analysis allows answering pertinent questions conditioning all establishing project: What (result to achieve or activity to realise)? Who (responsible and his collaborators)? How (resources)? When (time)? Where (place)?

We consider that informational resources are determining on the strategic level and on the communication one. The determination of these resources constitutes the base of all the information system. In fact, we reserve a particular importance to informational purpose and we consider all the parameters and all the functions like information that we must seize, treat and valorise. This information is evidently divided by the different activities taking into account their level.

\section{A. Presentation of OOPP method}

The OOPP method constitutes a tool of a global systemic modelling enabling to analyse a complex situation by its hierarchically decomposition until reaching an elementary level allowing an operational planning ${ }^{[5]}$.

This method, widely used in the planning of complex projects, involves many operators and partners. In Tunisia, it was used in Development projects financed by bilateral or multilateral co-operation mechanism (with Germany, Belgium, Canada, World bank...), in upgrading (Mise à Niveau) different structures (Training and Employment through MANFORME project, Organisation of the Tunis
Mediterranean Games 2001,...) and in restructuring private and public enterprises...

The two determining steps for an OOPP analysis are:

- The Scheme of Planing Project (SPP) that consist in establishing a global diagnostic of a situation by elaborating a Tree of Problems using a causal logic and by transforming it to a Tree of Objectives.

- The Scheme of Planing Activity (SPA) that, according to a logic « Medium - Detailed» lead to a hierarchic analysis of the results to achieve.

In fact, these steps constitute a preliminary action for establishing a Project that requires a global Piloting and Evaluation System (PES).

\section{B. Information Matrix associated to OOPP analysis}

The identification and analysis of exchanged information by the activities indicate the dynamics and the communication between the elements of the system that we propose to study or to manage. So, we define an information matrix ${ }^{[9][10][11]}$ that establishes a correlation between activities and their information. The information concerning an activity can be classified in two categories:

- An imported information by an activity is supposed to be available : it is either produced by an other activity of the system, or coming from outside,

- The produced information by an activity reflects the state of this activity. This last information may be exploited by other activities of the project.

In fact, the produced information by an Activity can be considered like a transformation of imported information by this Activity.

In order to specify these information, we define an information matrix associated to OOPP analysis permitting to:

- determine the relations between the activities or between the concerned structures,

- identify the information sources,

- determine the manner in which the information is exploited.

To make sure of the quality of information system, we define some logic-functional rules reflecting the coherence, the reliability and the comprehensiveness of the analysis by an information matrix in which the lines are relating to Activities and the columns to information. This matrix is constituted like this:

- the first line is reserved to the first activity A1,

- the first column is reserved to the first information If 1 associated to this activity, 
- if If1 is imported by A1, we inscribe « $0 »$ in the corespondent box, if it's produced by A1, we inscribe « $1 »$,

- we pass after that to the second information If 2 and we associate the corespondent binary character : « $0 »$ if the information is imported by the activity A1 and « $1 »$ if it's produced by the same activity,

- we proceed in the same way until all the information concerning A1 are exhausted,

- we pass after that to the second line corespondent to the second activity A2,

- if If1 concern A2, we inscribe the corespondent binary number ( 0 or 1 according to this information is imported or produced), otherwise, we leave a blank in the corespondent box, then we add the new information that concern the current activity,

- we follow the same step as far as exhausting of all activities and of all corespondent information.
We finally construct progressively a matrix of big dimension if the system is complex; it's constituted of $« 0 », \ll 1 »$ and «blank ».

\section{Model OOPP of cereal grading system}

The model of cereal grading system developed is complex. The OOPP method applied to this system has enabled, by its steps of analysis and planning, to understand better and better the description of this model and to facilitate after that the different expressions of relations constituting this model.

The global objective of the model: Cereal grading system assured lead to an analysis of the different steps proceeded in the evaluation system of cereals. A Tree of Objectives (Fig.1) modelling the cereal grading system is presented after validation by the experts.

An analysis of imported and produced information of cereal grading system was done and an associated glossary of this analysis was established.

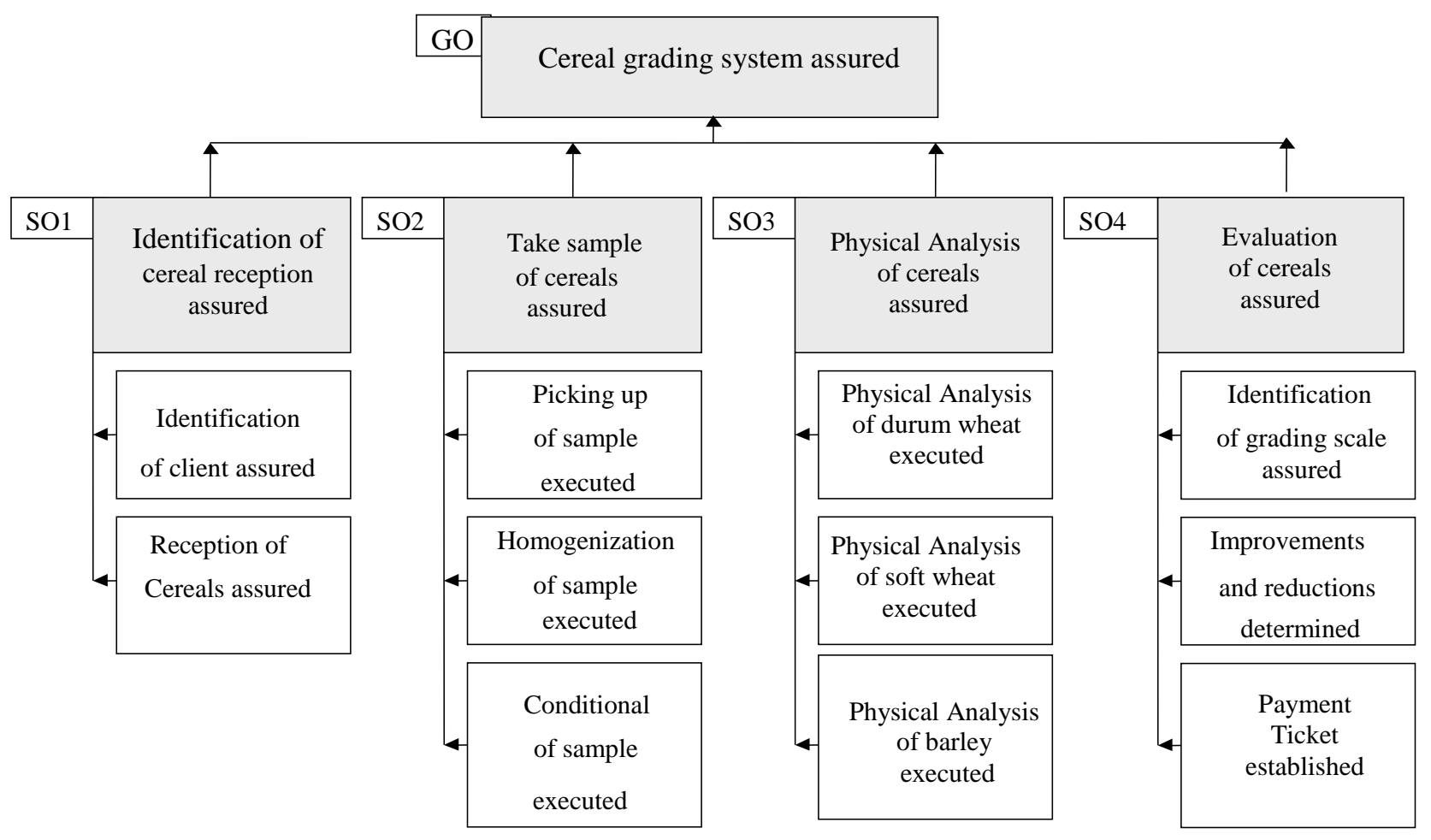

Fig.1- Tree of objectives of the cereal grading system

\section{Information matrix of cereal grading system}

In our approach, we consider every element of cereal grading system (Grading Parameters, Cereal variety, Reception ticket, demand of analysis, Analysis ticket, Payment ticket, Cereal sampling ticket...) like an information that can be expressed according to other information (Number of order, date, quantity...).
By exploiting the precedent information matrix defined, we constitute an "Information Matrix of Cereal Grading System» (IMCGS) where we give in the last column the different relations excising this system.

The information matrix associated to the model of cereal grading system, allows first to determine the relations between the activity defined in the descrip- 
tive table of tree of objectives, and secondly to identify and to exploit the information sources that constitute the different parameters of the model.

The complete OOPP analysis of cereal agreage system released 263 activities giving 279 informations. We distinguish various types of information source: declarative (name, $\mathrm{N}^{\circ}$ Lot...), measure (Specific weight, Percentage of impurities, time...), data base (Grading scale, Sample protocol, Homogenisation protocol, Basic price...), valorisation (Improvement value, Reduction value, Net price...).
The table Tab1 presents, in a linear form, some parts of analysis of Specific Objective 4 (SO4) and precise the information field concerning activities and specifying the imported information (Imp.Inf) and the produced information (Prod.Inf). We present in the table Tab2 a part of the information matrix IMCGS relative to $\mathrm{SO} 4$.

Every imported or produced information by an activity is codified: $\mathrm{N}^{\circ} \mathrm{AT}$ (number of analysis ticket), $\mathrm{N}^{\circ} \mathrm{PT}$ ( $\mathrm{N}^{\circ}$ of payment ticket), NatCer (cereal nature), $\mathrm{N}^{\circ}$ LtCer (number of cereal lot), VAP (value of grading parameter), BPQ1 (basic price per quintal)...

\begin{tabular}{|l|l|l|l|l|}
\hline$N^{\circ}$ & Code of activity & Activity & Imp.Inf & Prod.Inf \\
\hline
\end{tabular}

\begin{tabular}{|c|c|c|c|c|}
\hline 179 & $\mathrm{SO} 4$ & Evaluation of cereals assured & $\mathrm{N}^{\circ} \mathrm{AT}$ & $\mathrm{N}^{\circ} \mathrm{PT}$ \\
\hline 180 & R4.1 & Identification of agreage scale assured & $\begin{array}{l}\text { NatCer, } \\
\mathrm{N}^{\circ} \mathrm{LtCer}, \\
\text { VPA, BPQ1 }\end{array}$ & \\
\hline 181 & A4.1.1 & Identify the grading scale of durum wheat & & $\mathrm{GSc}_{1}$ \\
\hline 182 & A4.1.2 & Identify grading scale of soft wheat & & $\mathrm{GSc}_{2}$ \\
\hline 183 & A4.1.3 & Identify grading scale of barley & & $\mathrm{GSc}_{3}$ \\
\hline 184 & $\mathrm{R} 4.2$ & Improvements and reductions determined & & \\
\hline 185 & A4.1.1 & Identify the improvements to add to basic price & & \\
\hline 186 & S4.1.1.1 & Identify the codes of improvements & & CdImp \\
\hline 190 & S4.1.1.2 & Identify the improvements values & & VImp \\
\hline 191 & T4.1.1.2.1 & $\begin{array}{l}\text { Identify the improvements values of grading } \\
\text { scale of durum wheat }\end{array}$ & & VImp $_{1}$ \\
\hline 192 & T4.1.1.2.2 & $\begin{array}{l}\text { Identify the improvements values of grading } \\
\text { scale of soft wheat }\end{array}$ & & $\mathrm{VImp}_{2}$ \\
\hline 193 & T4.1.1.2.3 & $\begin{array}{l}\text { Identify the improvements values of grading } \\
\text { scale of barley }\end{array}$ & & $\operatorname{VImp}_{3}$ \\
\hline 194 & A4.1.2 & $\begin{array}{l}\text { Identify the reductions to reduce from base price } \\
\text { base }\end{array}$ & & \\
\hline 195 & S4.1.2.1 & Identify the codes of reductions & & CdRed \\
\hline 199 & S4.1.2.2 & Identify the reductions values & & VRed \\
\hline 200 & T4.1.2.2.1 & $\begin{array}{l}\text { Identify the reductions values of grading } \\
\text { scale of durum wheat }\end{array}$ & & $\operatorname{VRed}_{1}$ \\
\hline 201 & T4.1.2.2.2 & $\begin{array}{l}\text { Identify the reductions values of grading } \\
\text { scale of soft wheat }\end{array}$ & & $\operatorname{VRed}_{2}$ \\
\hline 202 & T4.1.2.2.3 & $\begin{array}{l}\text { Identify the reductions values of grading } \\
\text { scale of wheat of barley }\end{array}$ & & $\operatorname{VRed}_{3}$ \\
\hline 203 & $\mathrm{R} 4.3$ & Payment ticket established & & \\
\hline 204 & A4.3.1 & Cereal price determined & & \\
\hline 205 & S4.1.3.1 & Determine the total of improvements & & TotImp \\
\hline 206 & T4.1.3.1.1 & $\begin{array}{l}\text { Determine the total of improvements of du } \\
\text { rum Wheat }\end{array}$ & & TotImp $_{1}$ \\
\hline 207 & T4.1.3.1.2 & $\begin{array}{l}\text { Determine the total of improvements of soft } \\
\text { Wheat }\end{array}$ & & TotImp $_{2}$ \\
\hline
\end{tabular}




\begin{tabular}{|c|c|c|c|}
\hline 208 & $\mathrm{~T} 4.1 .3 .1 .3$ & $\begin{array}{l}\text { Determine the total of improvements of } \\
\text { barley }\end{array}$ & TotImp $_{3}$ \\
\hline 209 & S4.1.3.2 & Determine the total of reductions & TolRed \\
\hline 210 & $\mathrm{~T} 4.1 .3 .2 .1$ & $\begin{array}{l}\text { Determine the total of reductions of durum } \\
\text { wheat }\end{array}$ & TolRed $_{1}$ \\
\hline 211 & $\mathrm{~T} 4.1 .3 .2 .2$ & $\begin{array}{l}\text { Determine the total of reductions of soft } \\
\text { wheat }\end{array}$ & TolRed $_{2}$ \\
\hline 212 & $\mathrm{~T} 4.1 .3 .2 .3$ & Determine the total of reductions of barley & TolRed $_{3}$ \\
\hline 213 & S4.1.3.3 & Determine the gross price & GP \\
\hline 217 & S4.1.3.4 & Determine the deduction & Ded \\
\hline 221 & S4.1.3.5 & Determine the net price & NP \\
\hline 222 & T4.1.3.5.1 & Determine the net price of durum wheat & $\mathrm{NP}_{1}$ \\
\hline 223 & $\mathrm{~T} 4.1 .3 .5 .2$ & Determine the net price of soft wheat & $\mathrm{NP}_{2}$ \\
\hline 224 & $\mathrm{~T} 4.1 .3 .5 .3$ & Determine the net price of barley & $\mathrm{NP}_{3}$ \\
\hline
\end{tabular}

Tab1. Analysis of the Specific Objective 4

\begin{tabular}{|l|l|l|l|l|l|l|l|l|l|l|l|l|l|l|}
\hline $\mathbf{N}^{\circ}$ & Code Unf & $\mathbf{2 2 3}$ & $\mathbf{2 2 4}$ & $\mathbf{2 2 5}$ & $\mathbf{2 2 7}$ & $\mathbf{2 2 8}$ & $\mathbf{2 2 9}$ & $\mathbf{2 3 5}$ & $\mathbf{2 3 6}$ & $\mathbf{2 3 7}$ & $\mathbf{2 3 9}$ & $\mathbf{2 4 0}$ & $\mathbf{2 4 1}$ & \\
\hline
\end{tabular}

\begin{tabular}{|c|c|c|c|c|c|c|c|c|c|c|c|c|c|c|}
\hline 1 & T4.1.3.1.1 & 1 & & & & & & & & & & & & $\begin{array}{l}\text { TotImp }_{1}=\mathrm{VImp}_{1.1+} \mathrm{VImp}_{1.2+\ldots .+} \\
\text { VImp }_{1.14}\end{array}$ \\
\hline 2 & T4.1.3.1.2 & & 1 & & & & & & & & & & & $\begin{array}{l}\operatorname{TotImp}_{2}=\mathrm{VImp}_{2.1}+\mathrm{VImp}_{2.2+\ldots .+} \\
\text { VImp }_{2.12}\end{array}$ \\
\hline 3 & T4.1.3.1.3 & & & 1 & & & & & & & & & & $\begin{array}{l}\operatorname{TotImp}_{3}=\operatorname{VImp}_{3.1}+\operatorname{VImp}_{3.2}+ \\
\operatorname{VImp}_{3.3}+\mathrm{VImp} \mathrm{II}_{3.4}\end{array}$ \\
\hline 4 & T4.1.3.2.1 & & & & 1 & & & & & & & & & $\begin{array}{l}\operatorname{TolRed}_{1}=\operatorname{VRed}_{1.1}+\operatorname{VRed}_{1.2+\ldots .+} \\
\operatorname{VRed}_{1.14}\end{array}$ \\
\hline 5 & T4.1.3.2.2 & & & & & 1 & & & & & & & & $\begin{array}{l}\operatorname{TolRed}_{2}=\operatorname{VRed}_{2.1}+\operatorname{VRed}_{2.2+\ldots .+} \\
\operatorname{VRed}_{2.12}\end{array}$ \\
\hline 6 & T4.1.3.2.3 & & & & & & 1 & & & & & & & $\begin{array}{l}\operatorname{TolRed}_{3}=\operatorname{VRed}_{3.1+} \operatorname{VRed}_{3.2} \\
+\operatorname{VRed}_{3.3+} \operatorname{VRed}_{3.4}\end{array}$ \\
\hline 7 & $\mathrm{~T} 4.1 .3 .5 .1$ & 0 & & & 0 & & & 0 & & & 1 & & & $\begin{array}{l}\mathrm{NP}_{1}=\mathrm{GP}_{1}+\text { TotImp }_{1}-\text { TolRed }_{1-} \\
\text { Ded }_{1}\end{array}$ \\
\hline 8 & T4.1.3.5.2 & & 0 & & & 0 & & & 0 & & & 1 & & $\begin{array}{l}\mathrm{NP}_{2}=\mathrm{GP}_{2}+\text { TotImp }_{2}-\text { TolRed }_{2-} \\
\mathrm{Ded}_{2}\end{array}$ \\
\hline 9 & $\mathrm{~T} 4.1 .3 .5 .3$ & & & 0 & & & 0 & & & 0 & & & 1 & $\begin{array}{l}\mathrm{NP}_{3}=\mathrm{GP}_{3}+\text { TotImp }_{3}-\text { TolRed }_{3}- \\
\mathrm{Ded}_{3}\end{array}$ \\
\hline
\end{tabular}

Tab2. Example of the IMCGS relative to the Specific Objective 4

The application of the logic-functional rules previously indicated permit to make sure of the coherence and of the comprehensiveness of the analysis and this according to an iterative approach. This approach was applied to establish a new cereal grading system using a fuzzy logic ${ }^{[27][28] ~[29] . ~}$

\section{CONCLUSION}

The complexity of the cereal grading system and the important number of the information intervening in its constitution enables to elaborate a systemic method allowing the facilitating of system.

The OOPP method of analysis that we extended was permit to describe the information exchanges between the different elements of cereal grading system and to define the different parameters intervening in the constitution of the model. An information matrix associated to this analysis method of cereal grading model has allowed to identify the information sources and to determine the relations between the activities, permitting then a cereal evaluation and a contribution on the hand, to reduce the conflict or non objectively representatives situations and on the other hand to establish consensual and more objective support.

This kind of analysis enables to specify the information system in order to elaborate a management and conduct tools of projects; then the devel- 
opment of the data processing supports will be facilitated.

\section{REFERENCES}

[1] Direction de la promotion du secteur, Rapport d'activité de l'Office des Céréales, Tunis, Mars 98.

[2] JORT $n^{\circ} 4$, décret $n^{\circ} 2549$, Prix et modalités de paiement du stockage et rétrocession de céréales, 1996.

[3] S. Jlidi, Démarche et résumé du Plan Directeur de Stockage ( $2^{\text {ème }}$ phase 1998-2003), Étude CNEA, Tunis 1998 .

[4] M. Annabi, Plan Directeur de Stockage des Céréales, Atelier PIPO, Office des Céréales, Sept 98.

[5] M. Landry, C. Banville, Caractéristiques et balises d'évaluation de la recherche systémique, Revue Tunisienne des Sciences de Gestion, vol.2, $\mathrm{N}^{\circ} 1$ 2000.

[6] M. Annabi, Formation à Distance : pour quel Besoin ? Symposium International sur la formation de l'ingénieur, Conseil de l'Ordre des Ingénieurs, Tunis 26-27 mai 1999.

[7] Administration Générale de la Coopération au DévelOOOPPement, Manuel pour l'application de la «Planification des Interventions Par Objectifs (PIPO)», 2ème Edition, Bruxelles 1991.

[8] M. Annabi, Approche systémique de l'entreprise, Cours, INSAT, 2001.

[9] M. Souissi, Thèse d'État, Faculté des Sciences de Tunis, 2002.

[10] F. Bezaouia, ARENA et la simulation du flux : Application à la restauration d'athlètes, ENIS, Oct 2001

[11] Y. Ben Salem, Modélisation et commande d'une structure de réfrigération photovoltaïque, DEA, ENIS, Janv 2002.

[12] P. Cavelery, Soft Systems Thinking: A Precondition for Organizational Learning, Human Systems Management, 259-267, 1994.

[13] M. Hesse, Models of Method in the Natural and Social Sciences, Methodology and Science, 163178, 1975.

[14] M.C. Jackson, Beyond the Fads: Systems Thinking for Managers, Systems Research, 25-42, 1995.

[15] M. Landry, A note on the Concept of Problem, Organization Studies, 315-343, 1995.

[16] J. Kiner, J.P. Claveranne, Relire les systèmes de santé par les activités et les processus, Gestions hospitalières, $\mathrm{N}^{\circ} .393,87-9$, France 2000.
[17] A.Strohmeier, D.Buchs, Génie logiciel : principes, méthodes et techniques, Presses polytechniques et universitaires Romandes, Lausane 1996.

[18] P. Jaulent, Génie logiciel les méthodes, Edition : Armand Colin, Paris 1992.

[19] Office des Céréales, Procédure d'échantillonnage des céréales, Novembre 2000.

[20] Office des Céréales, Poids spécifique : méthode de détermination au nilémalitre, Mai 2001.

[21] ISO 950, Norme d'échantillonnage des céréales, 1979.

[22] NT 51.61 ENR, Céréales : détermination de la masse volumique, 1993.

[23] NT 51.02, Céréales : Définition des impuretés, Paris 1983.

[24] NT 51.21 ISO 712-1985, Céréales et produits céréaliers : détermination de la teneur en eau, 1989.

[25] NT 51.27 ISO 950-1979, Céréales : échantillonnage des grains, 1990.

[26] ISO 7970, Blé tendre : spécifications, Bordeaux 1989.

[27] M.N.Lakhoua, J.Zrida, A.Haddad, M.Annabi, Application de la logique floue à l'agréage des céréales, Revue Française de Gestion Industrielle, Vol.21, N${ }^{\circ}$, Mars 2002.

[28] M.N.Lakhoua, J.Zrida, M.Annabi, L’Agréage des céréales par l'Office des Céréales de Tunisie : Proposition d'une classification des échantillons de céréales par la logique floue, Revue Industries des céréales, $\mathrm{N}^{\circ} 127$, Avril / Mai 2002.

[29] M.N.Lakhoua, J.Zrida, M.Annabi, Application de la logique floue au contrôle du système d'agréage des céréales, CIFA'2002, Nantes 2002.

[30] S. Nouaigui, Formulation simplifiée d'un barème d'agréage de blé dur et tendre tunisien, Revue de l’INAT, Vol.7 N², Décembre 1992.

[31] Canadien International Grains Institute, Grains \& Oilseeds, Volume II, Canada 1993.

[32] Grain Research Laboratory, Quality of Western Canadien Wheat Exports, Canada, Cargo Bulletin $\mathrm{N}^{\circ} 277$, April 1995.

\section{Creative Commons Attribution License 4.0 (Attribution 4.0 International, CC BY 4.0)}

This article is published under the terms of the Creative Commons Attribution License 4.0 https://creativecommons.org/licenses/by/4.0/deed.en_US 